\title{
PRÁTICAS LÚDICAS X EDUCAÇÃO AMBIENTAL: CONTRIBUINDO PARA A CONSCIENTIZAÇÃO NA ESCOLA ESTADUAL RUY PARANATINGA BARATA
}

\author{
Katia Mesquita da Silva ${ }^{1}$ \\ Maria Ludetana Araújo² \\ Rosely Cardoso $\mathrm{Maia}^{3}$ \\ Sabrina Ferreira Farias ${ }^{4}$ \\ Tatiene Germano Reis Nunes ${ }^{5}$
}

Resumo: No mundo atual deparamo-nos com um cenário em que os problemas relacionados ao meio ambiente e seus impactos na vida das pessoas são motivos de vários debates. Assim, o processo educativo poderá contribuir tanto para a superação do quadro atual, de degradação da natureza, quanto aos problemas socioambientais. O presente trabalho descreverá as experiências vivenciadas pelos estudantes da Escola Estadual Ruy Paranatinga Barata, localizada em Belém do Pará, onde a "Educação Ambiental" e que conta como eixo norteador em suas práticas, as atividades lúdicas, tornando o processo de aprendizagem muito mais prazeroso.

Palavras-chave: Práticas; Educação; Educação Ambiental.

1Universidade Federal do Pará. E-mail: kati.mesquita@hotmail.com

2 Universidade Federal do Pará. E-mail: ludetanaaraujo@yahoo.com.br

3 Universidade Federal do Pará. E-mail: ly-maia@hotmail.com

4Universidade Federal do Pará. E-mail: brina_spelman@hotmail.com

5 Universidade Federal do Pará. E-mail: tatienegermano@gmail.com 


\section{Introdução}

A partir da Lei de Diretrizes e Bases da Educação Nacional (LDB, 1996), diversas instituições de ensino passaram a repensar a formação oferecida aos jovens, com isso verificou-se uma maior inserção do Meio Ambiente e da Educação Ambiental (EA) no processo educacional. A sua relevância se deu por proporcionar um processo educativo amplo, ativo e permanente, necessário à formação do cidadão que busca a qualidade da educação, tanto para o direcionamento da formação do professor, quanto para a busca de melhoria da qualidade de vida para além do processo ensino aprendizagem.

Assim, a Educação Ambiental adentra neste espaço como uma possibilidade, que passa a atender às propostas implantadas pelo Brasil (1997), nos Parâmetros Curriculares Nacionais (PCNs), onde institui que além de informações e conceitos, a escola e seus professores, devem trabalhar com atitudes, formação de valores bem como o ensino e a aprendizagem de habilidades e procedimentos. Considerando que o processo educativo pode contribuir para a superação do quadro atual, de degradação da natureza, e dos problemas socioambientais, vê-se na educação ambiental uma ferramenta para proporcionar um desenvolvimento com qualidade, mais justo e com equidade social, a partir de uma participação ativa.

$\mathrm{Na}$ atual conjuntura, a educação passa por diversas dificuldades, como a falta de estímulo dos professores, a desvalorização da profissão, a falta de qualidade da educação. Entretanto, a escola ainda é o lugar mais adequado para trabalhar a relação homem-ambiente-sociedade, sendo um espaço de excelência para formar um homem novo, crítico e criativo, com uma nova visão de mundo que supere o antropocentrismo (CARVALHO, 2008).

Em virtude disso, a sociedade passou a notar a importância de trabalhar a temática referente ao meio ambiente de forma interdisciplinar ou como propõem os PCNs (BRASIL, 1997), como tema transversal, em função da sua relevância social, urgência e universalidade, visando ao estabelecimento de diretrizes para o currículo e, principalmente, formar uma consciência capaz de perceber a natureza como um bem precioso e que se não for levada a sério, a humanidade sofrerá ainda mais os efeitos do impacto ambiental.

Emerge, assim, a necessidade de compreender a EA como um processo educativo amplo e permanente, que adentra na realidade de cada pessoa, tornando-se um fator essencial tanto para a qualidade da educação como para o direcionamento da formação do professor e das crianças e jovens, tendo em vista que a abordagem disciplinar não abrange a complexidade do processo educativo, ou seja, é necessário que ambos (alunos e professores) compreendam que a EA deve ser trabalhada gradativamente, abrangendo todas as questões da sociedade, uma vez que não se muda concepções, hábitos e comportamentos a partir de algumas atividades (GUIMARÃES, 2004).

Dessa forma, uma vez instalado o projeto de intervenção pedagógica da educação ambiental, surge a possibilidade de questionar e investigar as práticas 
pedagógicas existentes, a sua realidade e a sua comunidade a partir das problemáticas levantadas, que possibilitarão o envolvimento da comunidade escolar (alunos, professores, técnicos e etc.) na busca por melhorias, bem como na construção de um espaço permanente de participação e de atuação, transformando a escola em um contexto de desenvolvimento, passando a ser considerada uma rede de apoio, uma vez que influenciará comportamentos, a expectativa de futuro e favorecerá o desenvolvimento intelectual, emocional e social do individuo positivo (POLETTO; KOLLER, 2008).

Nesse contexto, a Educação Ambiental deverá desenvolver na comunidade escolar uma preocupação constante com o meio ambiente, com uma percepção sólida de sua problemática, decorrente das adversidades concretas na busca por soluções que possibilitem uma melhoria em sua vida, conforme está sugerido na Agenda 21 (BRASIL, 2004). A escola e seus alunos são sujeitos na construção de uma nova racionalidade, pautada na questão ambiental, no entanto não os únicos, dado que a sociedade como um todo, possui a capacidade de colocar a educação ambiental no seu cotidiano escolar e viabilizar uma EA crítica (GUIMARÃES, 2004), que de uma maneira eficaz e comprometida com a ética socioambiental, estimule a participação de todos na construção de uma sociedade ambientalmente sustentável.

Essa participação deve possibilitar um olhar mais atento da realidade de cada aluno e da comunidade, estimulando assim, a participação e o resgate da cidadania, formando pessoas preocupadas com questões que vão além da "natureza", identificando a ampla crise ambiental e sua complexidade (LEROY \& PACHECO, 2006), bem como o seu caráter crítico-transformador (GUIMARÃES, 2004) e a unidade entre natureza-sociedade (LOUREIRO, 2006).

\section{Projetos Sociais: A responsabilidade socioambiental da Companhia Docas do Pará na Escola Estadual Ruy Paranatinga Barata}

A interação com outras pessoas ou grupos e a participação em situações novas, permite à criança perceber suas possibilidades, potencialidades e limitações, tendo em vista que participar de um grupo é uma aprendizagem muito enriquecedora e indispensável à uma boa integração social, assim a permanência em grupos ajuda as crianças a se conhecerem melhor, fazerem novas amizades e aceitarem as diferenças existentes. $E$, pensando no desenvolvimento biopsicossocial de crianças e jovens, instituições privadas e/ou públicas desenvolvem planos de ações com o intuito de promover o bem-estar, a socialização, a interação, a conscientização e ainda contribuem para o processo de ensino-aprendizagem dos mesmos através dos chamados projetos sociais.

A existência de entidades não-governamentais e sem fins lucrativos que possuem o perfil de resgatar a cultura através de oficinas que ofereçam uma educação prazerosa e lúdica, acabam por promover a retirada de crianças e 
jovens de situações consideradas adversas ao desenvolvimento da criança, como o envolvimento com drogas, a exposição à violência, à marginalização, dentre outros. Segundo Alexandre (2008), os alunos são resultados de experiências vividas, desse modo os projetos são voltados para o bem-estar da sociedade e, principalmente, possuem atividades voltadas para o âmbito escolar, reafirmando o compromisso de tentar encaminhar 0 jovem para um desenvolvimento sadio, resgatando a dignidade dos mesmos, além de ajudar a formar um ser humano mais crítico e consciente das suas tradições, cultura e da sociedade na qual está inserido.

Os projetos sociais e seus envolvidos (educadores, gestores, empresas, instituições educacionais, dentre outros) seguem elaborando projetos que beneficiem as comunidades, promovendo a educação livre e trazendo benefícios tanto no âmbito pessoal quanto no social, possibilitando, inclusive, discussões como "aceitar as diferenças" e a inserção dos jovens considerados excluídos, uma vez que o mercado de trabalho está cada vez mais exigente. Desse modo, a educação passou a ser sinônimo de construção, de mudanças e, principalmente, de um processo que abrange todas as etapas da vida do ser humano, pois amplia consciências e leva à mudança de atitudes. Nesse sentido, instituições educacionais e empresas (públicas ou particulares) fazem parcerias com o intuito de promover uma educação de qualidade e ainda chamar a atenção das empresas quanto à responsabilidade social, incentivando, o cuidado com o meio ambiente.

A Política Nacional de Educação Ambiental (1981), destaca em seu artigo $3^{\circ}$, inciso $\mathrm{V}$, que as empresas devem ter a responsabilidade de garantir a promoção de um processo educativo no campo da educação ambiental. Desse modo, a Companhia Docas do Pará - CDP/Terminal Petroquímico de Miramar em parceria com a Universidade Federal do Pará - UFPA, através do Grupo de Estudos em Educação, Cultura e Meio Ambiente - GEAM, firmaram o compromisso de desenvolver junto à comunidade do entorno da CDP, um projeto social que reafirmasse e garantisse o compromisso social da empresa com a comunidade, por meio de atividades diferenciadas que envolvessem as práticas educativas voltadas para os direitos humanos, a valorização cultural, a literatura e, principalmente, o meio ambiente, fazendo uso da arte-educação, da ludicidade e da reciclagem.

O projeto foi executado na Escola Estadual Ruy Paranatinga Barata, que funciona com turmas de ensino Fundamental - em tempo integral - e com a Educação de Jovens e Adultos (EJA). A escola está localizada em uma área próxima ao entorno da CDP e tem suas ações baseadas em uma política de intervenção socioambiental, a partir de saberes e práticas que são embasadas na Educação Ambiental, direcionando para o entendimento coerente e problematizado os problemas de ordem socioambientais, com possibilidades de 
intervenções qualificadas na comunidade no sentido de buscar soluções para a diminuição dos problemas referentes aos impactos ambientais da comunidade.

O projeto "CDP com a Escola Estadual Ruy Paranatinga no Paraiso dos Pássaros" tem como propósito inserir a responsabilidade socioambiental por meio de saberes e práticas educativas e já está presente na instituição a dois anos, contando com uma segunda versão do primeiro, onde se busca o fortalecimento desse enraizamento e a autonomia no fazer pedagógico socioambiental de professores, alunos, corpo técnico, familiares dos alunos e comunidade do entorno.

A Educação Ambiental trabalhada no projeto desenvolvido na referida escola, impõe uma postura crítica, participativa e que desmistifica o universo a ser trabalhado, chamando a atenção para a importância da preservação ambiental e ainda a utilização dos recursos naturais de forma responsável e de maneira menos agressiva ao meio ambiente, através de atividades realizadas em parceria com os gestores, professores, funcionários da escola, alunos, pais e a comunidade do entorno envolvendo a arte-educação, o teatro, a dança, a música e a reciclagem, com o intuito de formar consciência a respeito dos problemas ambientais.

A Escola Estadual Ruy Paranatinga Barata foi criada através da Portaria $\mathrm{N}^{\circ}$ 464/98-GS de 28 de março de 1998; onde oferece o nível de Ensino Fundamental de $1^{\circ}$ ao $5^{\circ}$ ano, em tempo integral e EJA, atendendo a $2^{a}$ etapa do ensino fundamental à $2^{\text {a }}$ etapa do ensino médio. $O$ prédio faz parte de um grande projeto criado no Governo de Fernando Collor de Mello, que visava o atendimento de crianças e adolescentes em áreas carentes em todo o Brasil, em horário integral, contudo o projeto de atendimento integral da escola está sendo efetivado pelo Governo do Estado nessa escola desde janeiro de 2012, que fica situada no Conjunto CDP e possui moradores advindos do remanejamento dos habitantes das áreas do Projeto Macrodrenagem. Escola Ruy Paranatinga e a Educação Ambiental: Trabalhando novas práticas

Zeppone (1999), afirma que em nossa sociedade a atribuição de transmitir os conhecimentos sistematizados ao longo do tempo é uma função da escola, pois reúne em grande número de pessoas por um período de tempo considerado razoável e é nesse ambiente dotado de conhecimento e saberes que a educação ambiental também acontece. Dessa forma, percebe-se a necessidade de repensar o trabalho desenvolvido dentro das entidades formais e não-formais, visto a urgência de inserir um processo mais ativo que estimule a participação da comunidade escolar como um todo e ainda chame a atenção para os problemas relacionados à preservação do meio ambiente.

Rodrigues e Malafaia (2009) em um estudo que buscou analisar as percepções ambientais de jovens e adultos de uma escola de Ensino Fundamental de Minas Gerais constataram que $81,8 \%$ dos jovens e adultos possuíam uma percepção ambiental pouco elaborada e de caráter "reducionista" e apenas 9,2\% uma concepção abrangente. Logo, este resultado pode se dar 
por meio das análises das experiências que reproduzem as concepções de mundo. Por estar associada às experiências, são necessários novos processos de intervenções e práticas, mais sustentáveis, ou seja, que visem à geração de soluções conserváveis e duradouras, gerando sua continuidade nas gerações seguintes, resultantes de um pensamento sistêmico.

Os autores supracitados afirmam que diversos aspectos da vida do ser humano, e até de uma nação, estão diretamente vinculados à qualidade do meio ambiente e de vida de suas populações, atuando como fator determinante no perfil da saúde de uma comunidade. Estudos demonstram que espaços urbanos, em especial, têm provocado impactos ambientais de grandes proporções em virtude das ações antropogênicas (MENDONÇA, 2002; GIATTI et al., 2004; BUCCHEN-FILHO, 2006; FIRMINO et al., 2011; SILVA et al.,2012).

Somam-se ainda como problemas socioambientais, o fato de que no Brasil ainda persiste uma demanda populacional que não consegue ser atendida a serviços adequados de saneamento básico, que atinge de forma mais severa a população de baixa renda, a qual reside em maior concentração nos pequenos municípios e nas regiões periféricas dos grandes centros urbanos e nas grandes metrópoles (SILVA et al., 2012).

Em virtude da realidade atual, são necessários novos processos de intervenções e práticas mais sustentáveis, ou seja, que visem à geração de soluções conserváveis e duradouras, gerando sua continuidade nas gerações seguintes, resultantes de um pensamento sistêmico, visto que na sociedade moderna o paradigma vigente nos levou à crise do conhecimento e por conseguinte, ao ambiental. Assim, surge a necessidade de repensar o trabalho desenvolvido dentro das entidades formais e não-formais, visto a urgência de inserir um processo mais ativo que estimule a participação da comunidade escolar como um todo, pois, segundo Maluf (2004), aprendemos a conviver, a ganhar ou a perder, a esperar a vez, a lidar com as frustrações e a aumentar a motivação para conseguir uma participação satisfatória.

Desse modo, as atividades de caráter lúdicas estão presentes tanto em salas de aula (da cidade ou do campo), como também nos hospitais e em projetos sociais, realizados por organizações não-governamentais, instituições privadas ou públicas que desenvolvem atividades educacionais voltadas para crianças e jovens, tendo a cultura do lúdico como eixo norteador, visto que o brincar é importante para o crescimento e desenvolvimento biopsicossocial dos mesmos, uma vez que as brincadeiras despertam a atenção e a curiosidade não só da criança, mas em qualquer ser humano, deixando-os livre para aprender (MALUF, 2004).

A criança que se encontra em situação de vulnerabilidade social, assim como todas as crianças, também brinca, usa a imaginação e a fantasia; sente o mundo por meio do corpo, constrói hipóteses e sentidos sobre sua vida, sobre o lugar onde vive e sobre si mesma, necessitando estar em contato com ouras culturas, com outros saberes e de forma descontraída e prazerosa que a ludicidade proporciona, levando-as a reflexão e a conscientização. 
Através da ludicidade entramos em contato com um universo imprescindível para o desenvolvimento de qualquer criança, que é o mundo do jogo, do brinquedo e da brincadeira, que quando utilizado pelo educador, seja ele social ou não, em suas atividades, pode proporcionar momentos de descontração e aprendizagem, muita das vezes se torna um sonho distante para as crianças que residem nas áreas periféricas de Belém. Para brincar, não precisa ter idade, raça ou religião, apenas brincar e deixar a vida acontecer de um jeito mais simples, aproveitar cada momento enriquecedor que a brincadeira proporciona, momentos esses que com o passar dos anos vão ficando cada vez mais de lado sem a devida importância que o lúdico tem na vida do ser humano de um modo geral.

\section{Práticas Lúdicas: Do ensino-aprendizagem à Conscientização Ambiental}

Segundo Brougére (2001), a infância é uma fase na qual se faz a apropriação de imagens e de representações diversas que vão transitando por diferentes canais, onde as suas fontes são muitas e o brinquedo com toda a sua especificidade acaba por se tornar uma dessas fontes. A experiência com relação à inserção do brincar e da cultura do lúdico na sociedade não vem de agora, segundo Friedman (2005), a linguagem do brincar caracteriza-se pela sua universalidade, ela é tão antiga quanto a existência do ser humano, atravessando o tempo e as fronteiras. Friedman (2005) menciona que o brincar, assim como a arte, o movimento, a expressão plástica, verbal e musical podem ser consideradas linguagens que facilita a comunicação entre si e com os adultos, promovendo a interação entre os grupos.

O brincar é um sistema de signos que vai representar de forma consciente e inconsciente a vida real e trás de volta a vida do ser humano; já a brincadeira assume uma função terapêutica, porque nessa atividade a criança pode exteriorizar seus medos, angústias problemas internos e revelar-se inteiramente, resgatando a alegria, a felicidade, a afetividade e o entusiasmo.

O processo de adaptação da criança em um ambiente novo que procura se esforçar para ficar bem no espaço coletivo, onde as relações, regras e limites são diferentes daqueles que ela conhece em casa, são facilitados através da brincadeira. Para Kishimoto (1998), do ponto de vista psicológico, o brincar está presente em todo o desenvolvimento da criança nas diferentes formas de modificação do seu comportamento: na formação da personalidade, nas motivações, necessidades, emoções, valores, interações entre criança-família e criança-sociedade estão associadas aos efeitos do brincar.

A utilização da ludicidade dentro e fora da sala de aula torna as atividades mais descontraídas e os conteúdos a serem ministrados mais fáceis de serem compreendidos em virtude do lúdico auxiliar na remoção de bloqueios no que se refere ao processo de ensino-aprendizagem do aluno. Nesse sentido, na sociedade atual vivemos em um contexto onde a Educação Ambiental (EA) é um tema cada vez mais discutido nas escolas brasileiras e em algumas delas há até 
uma carga horária destinada à conscientização ambiental dos alunos, com o intuito de informar, formar opinião e ensinar as futuras gerações como se utilizar dos recursos naturais de forma responsável, ajudando a preservar a natureza. Para Layargues (2002), a questão do lixo vem sendo mostrada por defensores do meio ambiente como um dos mais graves problemas ambientais urbanos na atual conjuntura, ao ponto de se proporem técnicas de enfrentamento de tal situação e, por conseguinte, um dos motivos que levam a execução de programas de educação ambiental na escola brasileira.

A todo o momento milhões de toneladas de lixo são depositadas de forma irresponsável na natureza contribuindo para a degradação de áreas de mata atlântica, poluição dos oceanos, mares e rios e ainda para a morte de milhares de espécies vivas em todo mundo. Surge, portanto, a preocupação em "dar" um destino adequado a esse lixo para que diminua os impactos ambientais causados na natureza, surgindo assim, em todo o mundo, campanhas em favor da reciclagem e da "Pedagogia dos 3R's" (Reduzir, Reutilizar e Reciclar). O Reduzir consiste em tentar reduzir a quantidade de lixo produzida, o "Reutilizar" incentiva o consumo de produtos que possuam embalagens que possam ser utilizadas outras vezes e o "Reciclar" busca transformar um produto-resíduo em outro, visando diminuir o consumo de matéria prima extraída da natureza.

Gadotti (2000) afirma que os problemas da atualidade, inclusive os de ordem ecológica, são provocados pela nossa maneira de viver, que é inculcada pela escola, pelo que ela seleciona ou não, pelos valores que ela passa a transmitir, pelos currículos e ainda, pelos livros didáticos. Dessa forma, precisase orientar da melhor forma possível os alunos em favor de uma educação que respeite os princípios da sustentabilidade e de uma ecopedagogia voltada para a preservação ambiental (Gadotti, 2000).

Todavia, levando em consideração que a educação é um processo que vai além das salas de aula e está presente em todas as etapas de nossas vidas, precisamos trabalhar a conscientização ambiental em todos os setores e lugares de nossa sociedade, pois a falta de conhecimento e também de consciência acaba por produzir impactos ambientais de proporções enormes e preocupantes. Desse modo, a escola enquanto instituição formadora, não deve ficar de fora deste trabalho em favor da vida.

As práticas educacionais que envolvem a ludicidade tornam-se imprescindíveis dentro e fora do âmbito educacional, no que concerne ao processo de ensino-aprendizagem, são a linha norteadora para se desenvolver com sucesso uma proposta com finalidades para o alcance de um objetivo dentro ou fora do âmbito escolar: mudar mentalidades, superar preconceitos, combater atitudes discriminatórias e ainda, aliadas às práticas desenvolvidas pelos 
educadores, ajuda a formar a consciência acerca dos problemas causados, principalmente decorrentes do "impacto ambiental".

\section{Da prática às vivências da Educação Ambiental: Relatos das Experiências}

Após uma conversa com os professores e funcionários da escola e, conforme as observações feitas durante as primeiras visitas da equipe participante do projeto observou-se que a maioria das crianças não conseguia trabalhar em grupo, eram extremamente agitadas, não possuíam qualquer preocupação com a questão ambiental (de reciclar os objetos descartados durante o lanche, por exemplo), não eram acostumadas a dar opinião a respeito de qualquer assunto, não demonstravam qualquer interesse por atividades manuais (pintura, desenho, esculturas etc.) e em alguns casos eram extremamente violentas durante as aulas-oficinas.

Com isso, pensou-se em um espaço que pudesse promover o incentivo à leitura, à socialização, à valorização cultural, o respeito ao próximo, à afetividade, à solidariedade e ao aprendizado de maneira descontraída, além de incentivar a conscientização ambiental do alunado e de toda comunidade escolar. E pensando em todos esses interesses a serem trabalhados, o espaço foi todo revitalizado e decorado com material reciclado, recolhido pelas crianças, alguns educadores e facilitadores do projeto e por ultimo, dividido em cantinhos temáticos, utilizando para isso a ajuda das mesinhas (que foram cedidas gentilmente pela direção da escola), pedaços de TNTs, latas de cervejas, copos de sorvetes, almofadas (confeccionadas com capas de sombrinhas e pedaços de esponjas), restos de E.V.A., pedaços de papelão (utilizados para a confecção de uma esteira), baldes de tintas (e aros de metais) foram utilizados para compor o ambiente. O resultado foi um espaço divertido, colorido e totalmente confeccionado por meio da reciclagem e que de certa forma, atendeu às expectativas dos educadores.

O início das atividades dentro da Instituição começou com a revitalização do espaço e a coleta de materiais recicláveis, para que fossem trabalhadas as oficinas e demais atividades junto ás crianças e jovens. Contudo, as primeiras aulas foram difíceis, pois as crianças não aceitavam dividir nada, muito menos trabalhar em grupos e ainda havia alunos que se recusavam a participar das atividades propostas. Surgiu, portanto, a necessidade de outro espaço, algo que ao mesmo tempo proporcionasse às crianças momentos de leitura e auxiliasse no processo de adaptação às atividades.

Surgiu o Cantinho da Leitura, onde ocorreu a maioria das oficinas literárias, que tinha como objetivo o incentivo à leitura. Tal espaço funcionou de maneira muito satisfatória, assim como os demais dentro da sala de Educação Ambiental, pois os alunos sentavam na pequena esteira e escolhiam um dos 
livros dentro dos cestos e diziam: "- é muito bom pra ler assim!" e "- quem dera que nas outras salas tivesse o mesmo espaço".

Os "cantinhos temáticos" também ajudaram as crianças com sintomas de hiperatividade, e outros tipos de necessidades educativas especiais, que ficavam muito contentes em ir para a sala de educação ambiental participar das atividades propostas. $\mathrm{O}$ espaço, logo chamado pelos professores e funcionários da escola, recebeu o nome de "sala de educação ambiental" ou "sala do GEAM", passou a atender as crianças e ao mesmo tempo guardar os materiais de apoio pedagógico de forma organizada e aconchegante tanto para as crianças quanto para os educadores que estavam ministrando as oficinas.

Na sala de Educação Ambiental foi suspenso o uso de carteiras e optouse por utilizar a esteira feita de papelão tanto na hora de contação de história, como na hora das atividades de registros (pintura, colagens, desenhos, produção textual, dentre outras), pois além de proporcionar mais espaço e incentivar a interação, também chamava a atenção para a reutilização de materiais em virtude da confecção da esteira ser de papelão.

A ideia funcionou com muita rapidez, visto que as crianças começaram a gostar de trabalhar nos espaços divididos no interior da sala e em grupos formados por até cinco crianças. Após as primeiras semanas, as crianças atendidas nos projetos literários, e seus professores, ao se depararem com a sala de educação ambiental toda ambientada e decorada, ficaram encantadas e algumas diziam: "- Nossa tia, essa nossa sala ficou lindinha!".

A todo o momento chegavam crianças, cujas turmas as oficinas não abrangiam, questionando: "- quando a nossa turma vai participar também?". Então esclarecemos que não seriam todas as turmas que participariam, tendo em vista que a equipe era pequena, mas que no próximo ano, caso o projeto fosse aprovado, seria estendido para mais turmas. Mais tarde, os professores fizeram o mesmo questionamento, pois o projeto já havia percorrido toda a escola.

As atividades de mobilização com os alunos se deram na forma de apresentação de vídeos educativos sobre o tema educação ambiental e revitalização do espaço pela equipe de facilitadores e os alunos da instituição, através do plantio de mudas e vasos confeccionados a partir da reciclagem de garrafas pet. No final do ano foi organizada uma grande culminância com todos os trabalhos realizados e desenvolvidos pelo projeto na escola: exposições, apresentações de cartazes e peças teatrais sobre as lendas amazônicas, que incentivava a valorização cultural e materiais como ornamentos natalinos, personagens do folclore amazônico e brinquedos confeccionados a partir da reciclagem feita pelos alunos e, teve ainda a apresentação de espetáculos envolvendo a música e a dança na escola.

No salão de entrada havia uma pequena exposição dos trabalhos feitos pelas crianças e seus educadores sobre o poeta e escritor paraense Ruy Paranatinga Barata bem como sobre a cultura paraense (comida, bebida, 
crenças). Por último, foi realizada uma exposição sobre as mulheres e personalidades femininas que apesar das dificuldades, obtiveram destaque no cenário mundial. Foram utilizados materiais como tintas guache, colas, pincéis, canetas hidrocor, papéis A4, cartolinas, dentre outros, além de materiais descartados e reaproveitados da própria escola como caixas e papelão. Os alunos também colaboram com a coleta levando rolos de papel higiênico, latas, bandejas de isopor para que fossem utilizados por eles durante as atividades da oficina de reciclagem.

\section{Considerações finais}

Aos poucos as práticas diárias dos educandos e até dos funcionários da escola foram mudando e ambos passaram a guardar material e a deixar na sala de educação ambiental de modo que pudessem ser reciclados e transformados em material durante as oficinas. Foi gratificante ver as serventes, os funcionários da limpeza, as crianças e até seus professores levando material (caixas de papelão, caixas de leite, garrafas pet, rolinhos de papel higiênico) para os baldes de coleta seletiva dentro da sala.

Os resultados foram apresentações de peças teatrais (envolvendo o folclore amazônico), apresentações de danças e de arte (produzida pelas crianças), e na sequência houve também apresentações dos professores e dos alunos de trabalhos que envolviam a temática da educação ambiental, como: "A história do Ipê" (que levava a reflexão sobre a importância de se preservar o meio ambiente). Desta forma o trabalho realizado na Escola Estadual Ruy Paranatinga Barata contou com oficinas de literatura, de contação de história, de reciclagem, capoeira, customização, além de também contar com os trabalhos realizados sobre a alimentação saudável e a higiene, tudo organizado e desenvolvido de forma lúdica, tornando as atividades mais prazerosas e mais fáceis de serem assimiladas. Assim, notamos um grande envolvimento das crianças, educadores, e de toda equipe de educadores da instituição com o intuito de colaborar para o bom andamento das atividades.

Também se verificou uma maior conscientização dos alunos e os demais membros da escola a cerca da temática ambiental, pois diminui-se a quantidade de "lixos" dentro da Instituição e ainda, houve um maior reaproveitamento de material que antes era deixado nas lixeiras ou descartados dentro e fora da escola por parte dos professores e equipe técnica. O que antes era encontrado pelos corredores como: caixas de sucos, papelão, restos de TNT; passou a ser sinônimo de "reutilização", dando ênfase a Política dos chamados 3R's: Reduzir, Reutilizar e Reciclar.

Assim, o Projeto na Escola Estadual Ruy Paranatinga Barata mostrou que é possível trabalhar a temática da Educação Ambiental de forma lúdica, utilizando saberes ligados á arte-educação, a música e a dança; pois as práticas voltadas para o lúdico além de incentivarem a concentração, a descontração e o crescimento biopsicosocial da criança e adolescente, também é um grande 
aliado quando o assunto é passar informações, formar consciência e principalmente, chamar a atenção para os problemas considerados "sérios" (para a maioria dos jovens).

Contudo, para que se possam reduzir os impactos no meio ambiente, tanto na acumulação de lixo, como na questão do esgotamento das fontes de recursos naturais, de nada adianta trabalhar e incentivar a reciclagem e os programas de coleta seletiva do lixo, se não houver um trabalho de internalização de novos hábitos e também de atitudes para que, em um futuro próximo, não haja mais lixo excessivo e a sua causa, o consumo desmedido, controlado. $E$ visto que a criança aprende melhor brincando, qualquer atividade desenvolvida dentro e fora do âmbito escolar em que o eixo norteador seja a "ludicidade", será recebida com sucesso.

\section{AGRADECIMENTOS}

À Companhia Docas do Pará e à Universidade Federal do Pará pelo apoio financeiro à pesquisa; à Escola Estadual de Ensino Infantil e Fundamental Ruy Paranatinga Barata, por tornar possível a execução do projeto.

\section{REFERÊNCIAS}

ALEXANDRE, D.J. A arte de Ensinar e Aprender. 1 ${ }^{a}$ Edição. São Paulo: Mundo Mirim, 2008.

BRASIL, Ministério da Educação. Secretaria de Educação Fundamental. Parâmetros Curriculares Nacionais. Introdução. Brasília: MEC/SEF, 1997. Disponível em: www.portal.mec.gov.br/seb/arquivos/pdf/livro01.pdf. Acesso em: 19/05/14.

BRASIL, Ministério da Educação. Ministério da Educação. Formando Comissão do Meio Ambiente e Qualidade de Vida na Escola: construindo Agenda 21 na Escola. Brasília: MEC, Coordenação Geral de Educação Ambiental, 2004.

BRASIL, Ministério do Meio Ambiente. Política Nacional do Meio Ambiente. Lei 6.938/81. Disponível em: www.mma.gov.br/estruturas/sqa pnla/ arquivos/46 10112008050406.pdf.

Acesso em: 19/05/2014.

BROUGÉRE, G. Brinquedo e Cultura. Coleção questões de nossa época. Vol. 43, 4를 Edição. São Paulo: Cortez, 2001.

BUCCHERI-FILHO, A.T. Qualidade ambiental no bairro Alto da XV, Curitiba/PR. 92 f. (Dissertação de Mestrado). Universidade Federal do Paraná, Curitiba, 2006. http://dspace.c3sl.ufpr.br:8080/dspace/handle/1884/3773 Acesso em: 19/05/2014.

CARVALHO, I.C.M. Educação Ambiental: a formação do sujeito ecológico. São Paulo: Cortez, 1994. 
DOUROJEANNI, Marc J. Antigos e novos efeitos do desenvolvimento sustentável na Amazônia: Existem Mudanças? Há esperança para o desenvolvimento sustentável? Anais da Conferência Internacional Amazônia 21: Uma agenda para um mundo sustentável. Anais da Conferência 21/ Coordenação UNAMAZ; Secretaria de Coordenação da Amazônia - Brasília: DMF Congressos, 1998. http://www.ufpa.br/unamaz/index arquivos/Page6808.htm Acesso em: 15/05/2014.

FIRMINO, P.F.; MALAFAIA, G.; RODRIGUES, A.S.L. Diagnóstico da integridade ambiental de trechos de rios localizados no municípios de Ipameri, sudeste do Estado de Goiás, através de um protocolo de avaliação rápida. Brazilian Journal of Aquatic Science and Technology, v. 15, n. 2, p. 1-12, 2011. http://www6.univali.br/seer/index.php/bjast/article/view/2102 Acesso em: 21/05/2014.

FRIEDMANN, A. O Universo Simbólico da Criança: Olhares sensíveis para a criança. Coleção Educação e Infância. Rio de Janeiro: Vozes; 2005.

GADOTTI, M. Perspectivas Atuais da Educação-Educação-Sociedade. I. Título. Porto Alegre: Artes Médicas Sul; 2000.

GIATTI, L.L.; ROCHA, A.A.; SANTOS, F.A.; BITENCOURT, S.C.; PIERONI, S.R.M. Basic sanitary conditions in Iporanga, São Paulo State, Brazil. Revista de Saúde Pública, v. 38, n. 4, p. 1-6, 2004. http://www.scielosp.org/pdf/rsp/v38n4/en 21088.pdf Acesso em: 16/05/2014.

GUIMARÃES M. Educação ambiental crítica. In: Identidades da educação ambiental, Brasília: Ministério do Meio Ambiente, 2004.

KISHIMOTO, Tizuco (org.). O Brincar e Suas Teorias. São Paulo. Editora Pioneira, 1998.

LAYARGUES, P. O Cinismo da reciclagem: o significado ideológico da reciclagem da lata de alumínio e suas implicações para a educação ambiental, Cortez, São Paulo: 2002.

LEROY, J.P.; PACHECO, T. Dilemas de uma educação em tempo de crise. In: LOUREIRO, C.F.B.; LAYRARGUES, P.P.; CASTRO, R. S. (Orgs). Pensamento Complexo, dialética e Educação Ambiental. São Paulo, Cortez, 2006.

LOUREIRO, F.; LAYARGUES, P.; CASTRO, R. (Orgs.) Educação ambiental: repensando o espaço da cidadania. São Paulo: Cortez, 2002.

MALUF, Â.C.M. Brincadeiras Para a Sala de Aula. Rio de Janeiro: Vozes; 2004.

MENDONÇA, F. Aspectos da problemática ambiental urbana da cidade de Curitiba/PR e o mito da "Capital Ecológica". GEOUSP - Espaço e Tempo, n. 2, p. 1-8, 2002. http://www.geografia.fflch.usp.br/publicacoes/Geousp/Geousp12/Geousp12 Fr anciscoMendonca.htm. Acesso em 15/04/2014. 
PARÁ. Secretaria de Educação - SEDUC. Escola Estadual Ruy Paranatinga Barata. Portaria N 464/98-GS, de 28 de março de 1998.

POLETTO, M.; KOLLER, S. H. Contextos ecológicos: Promotores de resiliência, fatores de risco e proteção. Estudos de Psicologia (Campinas), 25(3), 405-416, 2008. http://www.scielo.br/pdf/estpsi/v25n3/a09v25n3 Acesso em 17;05/2014.

RODRIGUES, A.S.L.; MALAFAIA, G. Degradação dos recursos Hídricos e Saúde Humana: Uma atualização. Revista Saúde e Ambiente/Health and Environment Journal, V. 10, N. 1, junho/2009. http://www.scielo.br/pdf/rsp/v36n3/10502.pdf. Acesso em: 23/05/2014.

SILVA, C.A.F.; MALAFAIA, G.; VEIGA, B.G.A.; CASTRO, A.L.A. Vulnerabilidade Ambiental: Estudo de caso em um Bairro no Município de Sales/ SP. Rev. Holos, ano 28, vol. 4, 2012. file:///C:/Users/L\%C3\%9ACIA/Downloads/881-3242-1PB\%20(2).pdf Acesso em: 29/052014.

ZEPPONNE, R.M.O. Educação Ambiental: teoria e práticas escolares. 1ª Ed.; Araraquara; JM Editora, 1999. 